Article

\title{
Compound-Specific Isotope Analysis (CSIA) Application for Source Apportionment and Natural Attenuation Assessment of Chlorinated Benzenes
}

\author{
Luca Alberti ${ }^{1, *}$ (D) , Massimo Marchesi ${ }^{1}$, Patrizia Trefiletti ${ }^{2}$ and Ramon Aravena ${ }^{3}$ \\ 1 Dipartimento di Ingegneria Civile ed Ambientale, Politecnico di Milano, Piazza Leonardo da Vinci, \\ 32-20133 Milano, Italy; massimo.marchesi@polimi.it \\ 2 Tethys S.r.l.-Indagini Geologiche-Ambientali, Viale Lombardia, 11-20131 Milano, Italy; \\ patrizia.trefiletti@tethys.srl \\ 3 Department of Earth and Environmental sciences, University of Waterloo, 200 University Ave. West, \\ Waterloo, ON N2L 3G1, Canada; roaravena@uwaterloo.ca \\ * Correspondence: luca.alberti@polimi.it; Tel.: +39-02-2399-6663
}

Received: 22 September 2017; Accepted: 1 November 2017; Published: 9 November 2017

\begin{abstract}
In light of the complex management of chlorobenzene (CB) contaminated sites, at which a hydraulic barrier (HB) for plumes containment is emplaced, compound-specific stable isotope analysis (CSIA) has been applied for source apportionment, for investigating the relation between the upgradient and downgradient of the $\mathrm{HB}$, and to target potential $\mathrm{CB}$ biodegradation processes. The isotope signature of all the components potentially involved in the degradation processes has been expressed using the concentration-weighted average $\delta^{13} \mathrm{C}$ of $\mathrm{CBs}+$ benzene $\left(\delta^{13} \mathrm{C}_{\text {sum }}\right)$. Upgradient of the $\mathrm{HB}$, the average $\delta^{13} \mathrm{C}_{\text {sum }}$ of $-25.6 \%$ and $-29.4 \%$ orere measured for plumes within the eastern and western sectors, respectively. Similar values were observed for the potential sources, with $\delta^{13} \mathrm{C}_{\text {sum }}$ values of $-26.5 \%$ for contaminated soils and $-29.8 \%$ for the processing water pipeline in the eastern and western sectors, respectively, allowing for apportioning of these potential sources to the respective contaminant plumes. For the downgradient of the $\mathrm{HB}$, similar $\mathrm{CB}$ concentrations but enriched $\delta^{13} \mathrm{C}_{\text {sum }}$ values between $-24.5 \%$ and $-25.9 \%$ were measured. Moreover, contaminated soils showed a similar $\delta^{13} C_{\text {sum }}$ signature of $-24.5 \%$, thus suggesting that the plumes likely originate from past activities located in the downgradient of the HB. Within the industrial property, significant $\delta^{13} \mathrm{C}$ enrichments were measured for 1,2,4-trichlorobenzene (TCB), 1,2-dichlorobenzene (DCB), 1,3-DCB, and 1,4-DCBs, thus suggesting an important role for anaerobic biodegradation. Further degradation of monochlorobenzene (MCB) and benzene was also demonstrated. CSIA was confirmed to be an effective approach for site characterization, revealing the proper functioning of the HB and demonstrating the important role of natural attenuation processes in reducing the contamination upgradient of the $\mathrm{HB}$.
\end{abstract}

Keywords: chlorobenzenes; compound-specific stable isotope analysis (CSIA); source apportionment; biodegradation; natural attenuation

\section{Introduction}

Chlorinated solvents pose significant risks to human health, and contaminated sites entail tremendous management costs [1,2]. As a consequence of their intense use as solvents, industrial intermediates, and pesticides (in the past, dichlorodiphenyltrichloroethane, DDT, was also produced from chlorinated aromatics), these compounds, and particularly chlorinated benzenes (CBs), are frequently encountered as soil and groundwater contaminants [3]. The characterization and remediation of contaminated sites involves high costs, estimated from 500 to 5 million euros on average per site 
(European Union (EU) data [1]); hence the application of the polluter pays principle (PPP) may become essential. The application of new approaches for the correct identification of the polluter is necessary particularly in the presence of potential multiple sources/polluters, and especially at mega-sites such as industrial areas or petrochemical plants [4]. Also known as "source identification", "fingerprinting", or "source apportionment" (SA hereafter), this approach is also important for site-restoration applications [5-9]. Frequently after remediation actions (e.g., plume or source containment by physical or hydraulic barriers (HBs)), a downgradient contamination can still be detected [10], and often it is crucial to understand the reasons for the ongoing contamination. Studies including SA may provide an understanding of whether the downgradient pollution is due to a failure of the remediation system, for example, failure of containment of the contaminants by the barrier [11,12], or rather is related to other external sources undiscovered during the characterization of the contaminated site belonging to some other industrial sites.

Compound-specific stable isotope analysis (CSIA) is one of the tools used for SA that has been accepted by the public authorities, including the United States Environmental Protection Agency (US EPA) [13]. Potentially, different polluters may be using (or storing) contaminants that may have a different initial isotopic composition for one or several elements characterizing the target molecule (carbon, chlorine or hydrogen in the case of chlorinated hydrocarbons). Different isotopic patterns generally aid in distinguishing between different contaminant plumes and eventually help to appoint plumes to their respective sources (SA) [5-9,13]. Furthermore, the use of CSIA enables the investigator to identify, and in some cases also quantify, natural attenuation processes such as biodegradation or abiotic reduction [14,15]. When contaminants are degraded in the environment, the ratio of stable isotopes may change (the "isotope fractionation"). Furthermore, molecules containing lighter isotopes tend to react more rapidly compared to those including heavy isotopes. Indeed, the extent of degradation can be estimated by evaluating changes in the stable isotope ratio of the remaining fraction [13]. In this context, CSIA has a pivotal application for contaminated sites where monitored natural attenuation (MNA) is applied [16]. MNA is most often used to reinforce other measures of active remediation, for example, source containment by physical or HBs or source treatment such as in situ chemical oxidation (ISCO) [17]. MNA is considered among the most valuable remediation actions for its wide applicability, the excellent cost/benefit relationship, and particularly for having the lowest environmental impact when compared to active systems practices [18].

In the specific case of the CBs, chemical transformations such as abiotic hydrolysis are generally considered to be limited $[19,20]$. Biodegradation processes on the other hand, both under aerobic and anaerobic conditions, can help to significantly reduce the concentrations of these contaminants in the subsurface. As a rule of thumb, highly chlorinated benzenes such as trichlorobenzenes (TCBs) have a tendency to undergo reductive dehalogenation [21]. Conversely, lower CBs such as monochlorobenzene (MCB) preferentially degrade via oxidative processes to complete mineralization [21]. Anaerobic degradation such as reductive dehalogenation appears to be up to 10 times faster than aerobic oxidation processes [3]; however, it may have the disadvantage of generating benzene as a final product of the biodegradation, which in turn is more toxic than the starting products [22]. In contrast to compounds such as chlorinated ethenes, for which there is a well-developed literature on CSIA applications, only few studies are available for CBs. Significant carbon enrichment factors were obtained in laboratory experiments under anaerobic conditions, ranging from $-0.8 \%$ to $-6.3 \%$ o for several CBs [22-26], which allows for the use of CSIA for tracing in situ biodegradation of CBs in contaminated anoxic aquifers. Kaschl et al. $[24,27]$ demonstrated MCB anaerobic biodegradation at two contaminated sites, while [28] investigated anaerobic biodegradation of dichlorobenzenes (DCBs) and MCB by interpreting CSIA results on the basis of an isotope mass balance approach. On the contrary, almost no isotope carbon fractionation for MCB and 1,2,4 TCB during aerobic biodegradation was demonstrated [23,24] —results that were confirmed by Liang et al. [25]. Thus, the lack of carbon isotope fractionation limits the use of carbon-CSIA for MNA applications in contaminated environments under oxic conditions. 
The present study examines the potential of CSIA for CBs, particularly DCBs (1,2-, 1,3- and 1,4-DCB) and $\mathrm{MCB}$, at a complex contaminated site where, in 2002, a HB was installed to contain contamination. CSIA in conjunction with hydrogeological data and contaminant concentrations has been applied for SA, to understand if the HB is effective in containing contaminants, and to evaluate the role of potential biodegradation processes on the contaminant distribution in the aquifer downgradient of the HB. Moreover, the origin and the fate of benzene has been investigated to discriminate between its presence as a primary contaminant or as a by-product of MCB biodegradation.

\section{Materials and Methods}

\subsection{Site Description}

The site, located in northern Italy, consists of two main areas: (i) the upgradient of the HB emplaced in 2002, and where a chemical manufacturing plant has been operating since the 1920s, producing pesticides and plastic products; and (ii) the downgradient of the HB, where a chemical waste management facility for hazardous waste has been in operation since the 1980s. (Figure 1). Located within a $2 \mathrm{~km}$-wide valley, the site is surrounded by other industrial properties to the north and west and by a river to the south.

The pesticides and plastic production plant was initially located in the eastern portion of the industrial property (old facilities area) during the first 60 years of its activity (Figure 1). Only at a later stage was the production area relocated to the western sector (active facilities), and by then all of the production system had undergone renovation (yellow area in Figure 1). Starting in 1995, the site underwent several environmental characterization and remediation activities, including the design and installation of a $\mathrm{HB}$ along the southern border of the chemical manufacturing plant (Figure 1).

The stratigraphy of the Quaternary sediments consists of very coarse sand and gravels (down to about $25 \mathrm{~m}$ below ground level (b.g.l.)), and sands and fine sands (from 25 to $60 \mathrm{~m} \mathrm{b.g.1.)} \mathrm{sitting} \mathrm{on}$ impermeable silts and clay (starting at $60 \mathrm{~m}$ b.g.l.). The alluvial deposits host an unconfined aquifer bounded at its sides by igneous rocks of low permeability. The water table is found at shallow depths, between 3 and $6 \mathrm{~m}$ b.g.l., and the direction of groundwater flow is north to south-west, mainly toward the HB and further beyond to the river (Figure 1). The aquifer properties were investigated with geotechnical laboratory probing, pumping (especially in the shallower $20 \mathrm{~m}$ of the aquifer), falling head, and single-point dilution tests. The shallow sand and gravel layer have a high hydraulic conductivity (from $1 \times 10^{-3}$ to $3 \times 10^{-3} \mathrm{~m} \mathrm{~s}^{-1}$ ), while in the underlying sandy layers, the hydraulic conductivity decreases progressively with depth from $2 \times 10^{-4}$ to $1 \times 10^{-5} \mathrm{~m} \mathrm{~s}^{-1}$.

A wide monitoring network consisting of 153 points within the shallow aquifer (down to $30 \mathrm{~m}$ b.g.1.) defines the study area. Previous chemical investigations performed regularly every 6 months for the last 15 years revealed several chlorinated solvents, including MCB, DCBs (1,2-, 1,3- and $1,4-\mathrm{DCB})$ and benzene with concentrations above the maximum concentration limit (MCL). Additional chlorinated compounds, referred to as chlorinated toluenes (2- and 4-chlorotoluene, and 2,3-, 2,4-, and 2,6-dichlorotoluene) and toluene were also detected (data not shown).

At the site, the contamination by chlorinated solvents is identified within three narrow plumes (Figure 1): one plume is located in the eastern portion and two are located in the western portion of the industrial property. All the plumes reach the HB at different locations (Figure 1).

The HB consists of 16 "well pairs", a combination of short wells from 3 to $10 \mathrm{~m}$ b.g.l. and deeper wells from 10 to $20 \mathrm{~m}$ b.g.l., designed to capture contaminants flowing in the more conductive and contaminated part of the aquifer. Despite the adopted containment system, relevant concentrations, particularly of $\mathrm{MCB}$, are still detected in the downgradient of the HB (Figure 1) and within the area for which the chemical waste management facility operated during the 1980s.

For an easier characterization of the study site, results are presented with regard to the two main sectors and identified by the site history and function together with the groundwater flow patterns (Figure 1): the eastern sector (i), where the old plant was located and operating until the 1980s; and 
the western sector (ii), where the facility is still operative. Moreover, throughout the manuscript, citing the upgradient and the downgradient is intended to refer to the HB (Figure 1), representative of the industrial property and the chemical waste management facility areas, respectively.

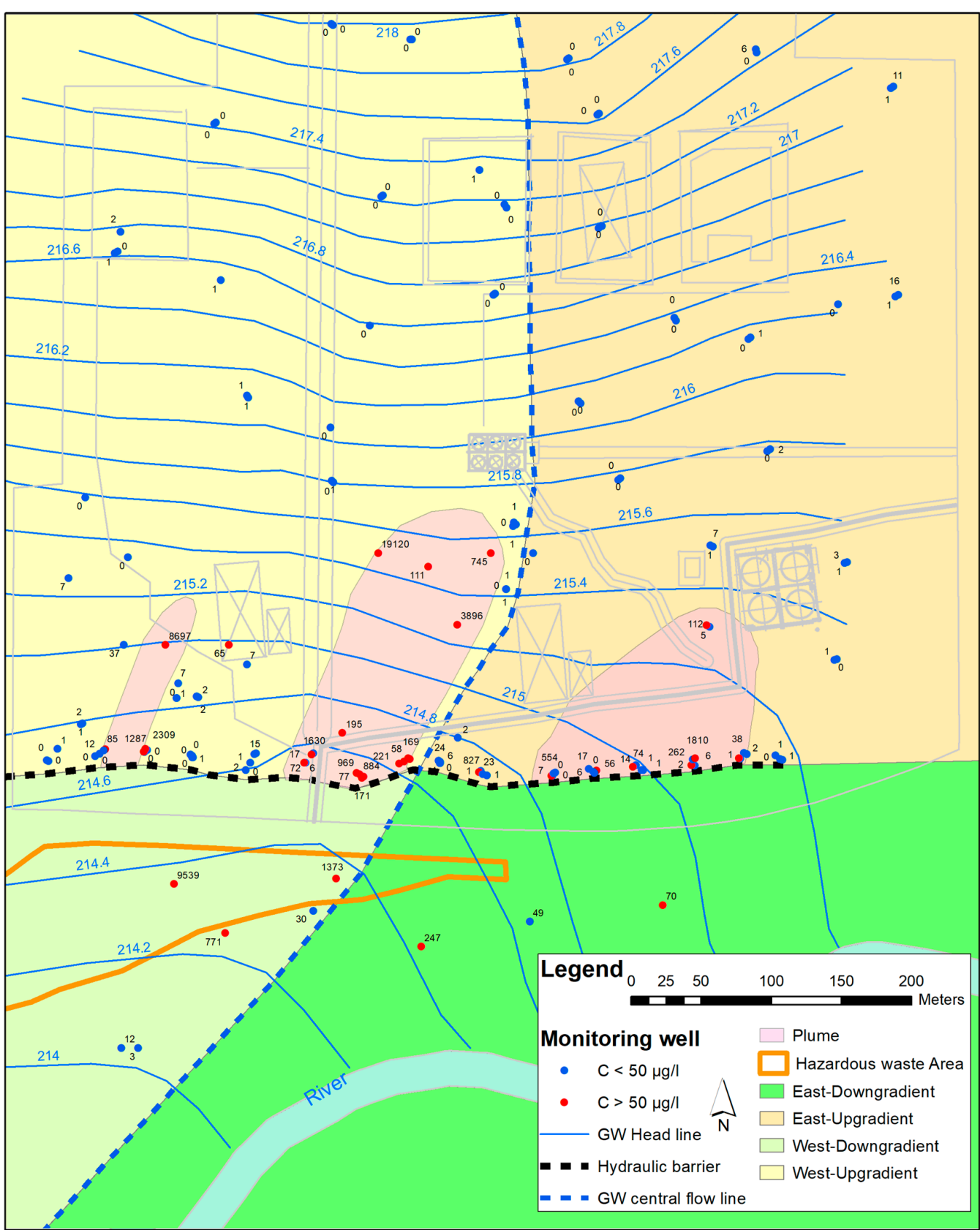

Figure 1. Groundwater flow and monitoring network in the shallow part of the aquifer $(<30 \mathrm{~m})$; concentrations refer to the sum of chlorobenzenes. Pink contours show the three narrow plumes located in the upgradient of the hydraulic barrier.

\subsection{Sampling and Geochemical Parameters}

In order to achieve the objectives of this study, groundwater was collected from 16 sampling locations. Wells were selected from the existing monitoring network (down to $30 \mathrm{~m}$ b.g.l.; Figure 2) and were known to show significant concentrations of chlorinated solvents. In addition, one sample representative of the processing water was collected (WP; Figure 2), as well as four soil samples (B-; Figure 2) required to investigate the potential sources' distribution. 
The groundwater flow and the distribution of contaminants refer to the shallow portion of the aquifer; the groundwater samples were processed for $\mathrm{CB}$, chlorinated toluene $(\mathrm{CT})$ and benzene concentrations, as well as CSIA and redox species characterization.

Field parameters, including dissolved oxygen (DO), were measured by a portable probe (WTW Multi 3430 IDS). The redox species, $\mathrm{SO}_{4}{ }^{2-}, \mathrm{S}^{2-}, \mathrm{NO}_{3}{ }^{-}$, and $\mathrm{NO}_{2}{ }^{-}$were measured by ion chromatography, whereas $\mathrm{Mn}$ (II), total iron $\left(\mathrm{Fe}_{\text {tot }}\right)$ and $\mathrm{Fe}$ (II) were determined by inductively coupled plasma-mass spectrometry.

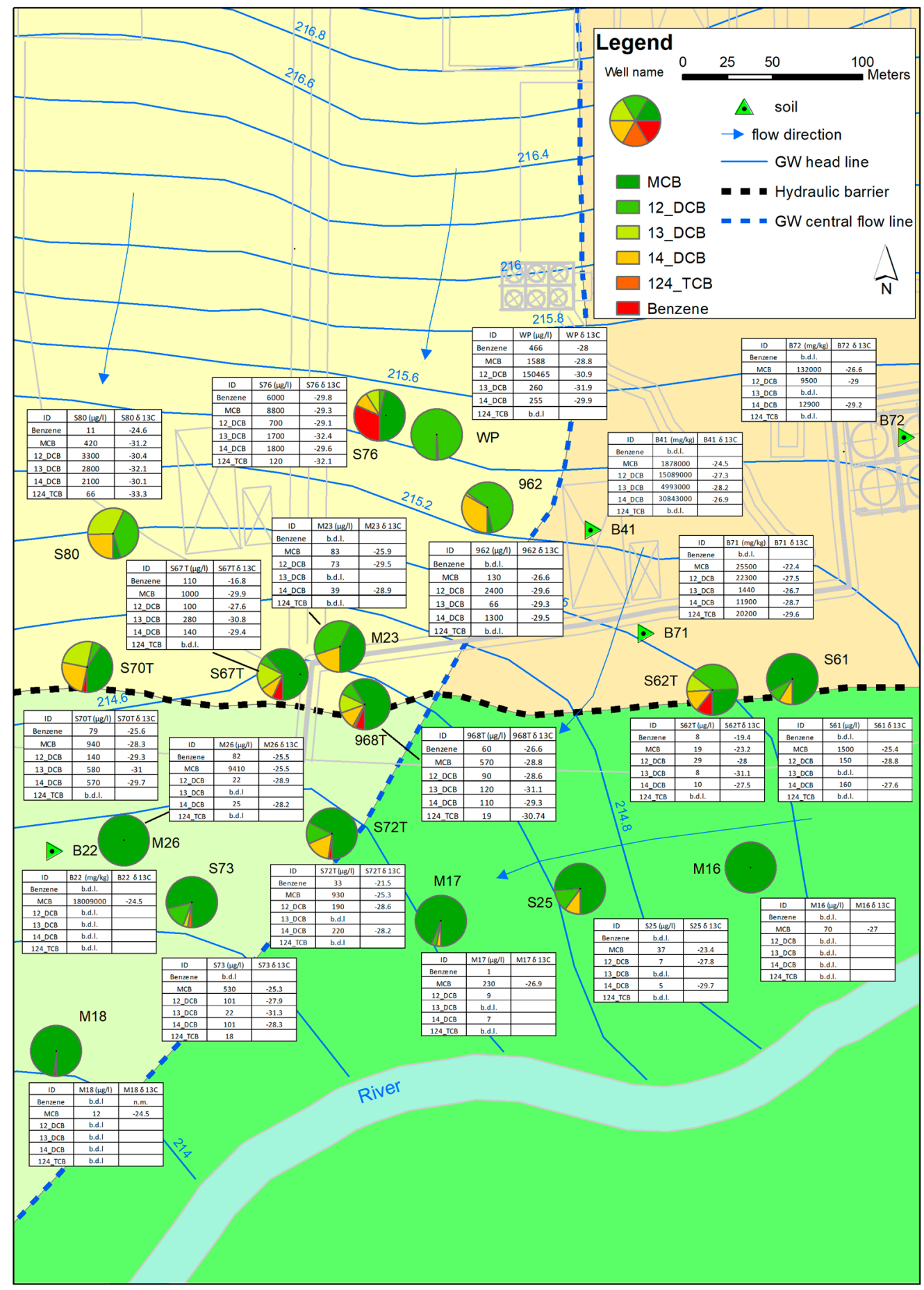

Figure 2. Map of locations used for sampling showing total chlorobenzene concentrations $\left(\mu \mathrm{L} \mathrm{L}^{-1}\right)$, $\delta^{13}$ Csum $(\% 0)$ and molar fraction distributions along the groundwater flow system. 


\subsection{Concentration and CSIA Analyses}

Concentrations of the target contaminants in groundwater samples were determined by headspace analysis using a gas chromatograph and were coupled to a mass spectrometer (Agilent Technologies, Santa Clara, CA, USA). The same procedure was applied for soil samples, subsequent to contaminant extraction by means of a non-polar solvent (pentane with an internal standard). Carbon isotope ratios of the target contaminants were determined by headspace solid-phase micro-extraction coupled to a gas chromatograph and to an isotope ratio mass spectrometer via a combustion interface (Thermo Fisher Scientific, Waltham, United States). Isotope data are reported using the delta notation, $\delta^{13}(\%)=\left(\left(R_{S} / R_{\text {std }}\right)-1\right) \times 1000$, where $R_{S}$ and $R_{\text {std }}$ are the ${ }^{13} \mathrm{C} /{ }^{12} \mathrm{C}$ ratios of the sample and the international standard, Vienna Pee Dee Belemnite (VPDB), respectively. It is intended that the terms "enriched" and "depleted" refer to the heavy isotope $\left({ }^{13} \mathrm{C}\right)$ consistently. The samples were analyzed in triplicate with a precision of between $0.1 \%$ and $0.5 \%$. All the analysis were performed at Isotope Tracer Technologies Europe Srl, Milan, Italy.

The concentration-weighted average $\delta^{13} \mathrm{C}$ of $\mathrm{CBs}+$ benzene $\left(\delta^{13} \mathrm{C}_{\text {sum }}\right)$ was calculated using Equation (1):

$$
\delta^{13} C_{\text {sum }}=\Sigma\left(C_{i} \times \delta^{13} C_{i}\right) / C_{\text {sum }}\left(C_{\text {sum }}-C B s\right)
$$

where $C_{i}$ and $\delta^{13} C_{i}$ are the molar concentrations and the carbon isotope composition of each compound. $\mathrm{C}_{\text {sum }}$ represents the total molar concentration of all contributors.

The error associated with the concentration-weighted average $\delta^{13} \mathrm{C}$ calculation was computed using the standard deviation of the isotope measurements (when not available, $0.5 \%$ was used) and a precision of $10 \%$ for the concentration analysis. On the basis of the error propagation, the following equation was adopted:

$$
\Delta \delta 13 \mathrm{C}_{\text {sum }}=\frac{\sqrt{\left[\Sigma\left(\mathrm{C}_{\mathrm{i}} \times \Delta \delta 13 \mathrm{C}_{\mathrm{i}}\right)^{2}+\Sigma\left(\left[\delta 13 \mathrm{C}_{\mathrm{i}}-\delta 13 \mathrm{C}_{\text {sum }}\right] \times \Delta \mathrm{C}_{\mathrm{i}}\right)^{2}\right]}}{\mathrm{C}_{\text {sum }}}
$$

To estimate the extent of biodegradation, a modified version of the Rayleigh equation was adopted, as follows:

$$
\mathrm{f}=\mathrm{e}^{\wedge}\left(\left(\delta^{13} \mathrm{C}_{\mathrm{i}}-\delta^{13} \mathrm{C}_{\text {source }}\right) / \varepsilon\right)
$$

where $\delta^{13} C_{i}$ and $\delta^{13} C_{\text {source }}$ are the isotopic compositions along the plume (at the monitoring point i) and at the source (initial) respectively, $\varepsilon$ represents the stable isotope enrichment factor, and $f$ is the remaining compound fraction, $\mathrm{C} / \mathrm{C}_{\text {initial }}[13]$.

\section{Results}

The presentation of geochemical and isotopic data is preceded by an overall site characterization on the basis of redox parameters. Then, the spatial distribution of the contaminants, molar fractions and the CSIA results are presented separately in this section. As previously mentioned, data are shown for the eastern and western sectors and upgradient or downgradient of the HB (Figures 1 and 2). All the available raw data are reported in Table 1. 
Table 1. Data summary. Redox species ( $\mathrm{mg} \mathrm{L}^{-1}$ ) and chlorobenzenes (CBs) and chlorinated toluenes (CTs) concentrations ( $\mu \mathrm{g} \mathrm{L} \mathrm{L}^{-1}$ and $\mu \mathrm{g} \mathrm{kg}^{-1}$ for groundwater and soil samples, respectively); isotope data $(\% \circ): \delta^{13} \mathrm{C}$ and $\delta^{13} \mathrm{C}_{\text {sum }}$. See Figure 2 for sample locations.

\begin{tabular}{|c|c|c|c|c|c|c|c|c|c|c|c|c|c|c|c|c|c|c|c|c|c|c|c|}
\hline & & & DO & $\mathrm{NO}_{2}{ }^{-}$ & $\mathrm{SO}_{4}{ }^{2-}$ & $\mathrm{Fe}_{\text {tot }}$ & $\mathrm{Fe}^{2+}$ & $\mathrm{Mn}^{2+}$ & МСB & $1,2-\mathrm{DCB}$ & 1,3-DCB & $1,4-\mathrm{DCB}$ & 1,2,4-ТCB & Benzene & CBs & CTs & МСB & 1,2-DCB & 1,3-DCB & & 1,2,4-TCB & Benzene & $8^{13} \mathrm{C}_{\mathrm{sum}}$ \\
\hline & & ID & \multicolumn{6}{|c|}{$\mathrm{mg} / \mathrm{L}$} & \multicolumn{8}{|c|}{$\mu \mathrm{g} / \mathrm{L}$ for $\mathrm{S}-\mathrm{M}-\mathrm{W}-$ and $\mu \mathrm{g} / \mathrm{Kg}$ for $\mathrm{B}-$} & \multicolumn{7}{|c|}{$\delta^{13} \mathrm{C}$ VPDB $(\%)$} \\
\hline \multirow{13}{*}{ 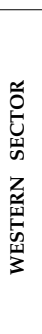 } & \multirow{8}{*}{ UPGRADIENT } & WP & $<0.1$ & 1.2 & 13 & 8.3 & 3.2 & b.d.l. & 1588 & 150465 & 260 & 255 & b.d.l. & 466 & 153034 & 21940 & -28.8 & -30.9 & -31.9 & -29.9 & & -28.0 & -30.9 \\
\hline & & S76 & $<0.1$ & 0.0 & 26 & 23.0 & 22.0 & b.d.l. & 8800 & 700 & 1700 & 1800 & 120 & 6000 & 19120 & 11145 & -29.3 & -29.1 & -32.4 & -29.6 & -32.1 & -29.8 & -29.7 \\
\hline & & S80 & $<0.1$ & 0.0 & 21 & 0.3 & 0.1 & b.d.l. & 420 & 3300 & 2800 & 2100 & 66 & 11 & 8697 & 7805 & -31.2 & -30.4 & -32.1 & -30.1 & -33.3 & -24.6 & -30.9 \\
\hline & & 962 & 0.3 & 0.1 & 34 & 5.0 & 1.9 & 0.3 & 130 & 2400 & 66 & 1300 & b.d.l. & b.d.l. & 3896 & 189 & -26.6 & -29.6 & -29.3 & -29.5 & n.m. & n.m. & -29.4 \\
\hline & & S70T & 0.8 & 0.3 & 29 & 10.0 & 4.9 & 0.4 & 940 & 140 & 580 & 570 & b.d.l. & 79 & 2309 & 4969 & -28.3 & -29.3 & -31.0 & -29.7 & n.m. & 25.6 & -29.1 \\
\hline & & S67T & 2.2 & 0.3 & 720 & 7.6 & b.d.l. & 0.8 & 1000 & 100 & 280 & 140 & b.d.l. & 110 & 1630 & 261 & -29.9 & -27.6 & -30.8 & -29.4 & n.m. & -16.8 & -28.6 \\
\hline & & $968 \mathrm{~T}$ & 0.3 & 0.1 & 1960 & 200.0 & 190.0 & 0.8 & 570 & 90 & 120 & 110 & 19 & 60 & 969 & 310 & -28.8 & -28.6 & -31.1 & -29.3 & -30.4 & -26.6 & -28.9 \\
\hline & & M23 & n.m. & n.m. & n.m. & n.m. & n.m. & n.m. & 83 & 73 & b.d.l. & 39 & b.d.l. & b.d.l. & 195 & b.d.l. & -25.9 & -29.5 & n.m. & -28.9 & n.m. & n.m. & -27.6 \\
\hline & \multirow{5}{*}{ DOWNGRADIENT } & S72T & $<0.1$ & 0.0 & 450 & 0.1 & 0.1 & 0.7 & 930 & 190 & b.d.l. & 220 & b.d.l. & 33 & 1373 & b.d.l. & -25.3 & -28.6 & & -28.2 & & -21.5 & -25.9 \\
\hline & & S73 & 0.3 & 4.0 & 103 & 0.1 & 0.1 & 0.7 & 530 & 101 & 22 & 101 & o.u.t. & b.d.l. & 771 & & -25.3 & $\begin{array}{l}-20.0 \\
-27.9\end{array}$ & -31.3 & -2 & & -21.5 & -25.1 \\
\hline & & M18 & $<0.1$ & 0.0 & 42 & 0.0 & 0.0 & b.d.l. & 12 & b.d.l. & b.d.l. & b.d.l. & b.d.l. & b.d.l. & 12 & $\begin{array}{l}\text { b.d.l. } \\
\text { b. }\end{array}$ & -24.5 & n.m. & & $\mathrm{n} . \mathrm{x}$ & & & -24.5 \\
\hline & & M26 & n.m. & n.m. & n.m. & n.m. & n.m. & n.m. & 9410 & 22 & b.d.l. & 25 & b.d.l. & 82 & 9539 & b. & -25.5 & -28.9 & & -28.2 & & -25.5 & -25.5 \\
\hline & & B22 & & & & & & & 18009000 & b.d.l. & b.d.l. & b.d.l. & b.d.l. & b.d.l. & 18009000 & b.d.l. & -24.5 & n.m. & $n . n$ & n.m. & n.m. & n.m. & -24.5 \\
\hline \multirow{7}{*}{ 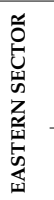 } & & B41 & - & - & - & - & - & - & 1878000 & 15089000 & 4993000 & 30843000 & b.d.l. & b.d.l. & 52803000 & & -24.5 & -27.3 & -28.2 & & & & -27.0 \\
\hline & & B72 & _- & - & - & - & _- & 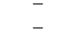 & 132000 & 9500 & b.d.l. & 12 & & & 15 & & -26.6 & -2 & & -2 & & & -26.9 \\
\hline & UPGRADIENT & B71 & & - & - & - & & - & 25500 & 22300 & 1440 & 11900 & 20 & b.d.l. & 81 & & -2 & -2 & -2 & -2 & -2 & & -26.1 \\
\hline & & 561 & 0.6 & 0.3 & 560 & $\overline{9.0}$ & $\overline{7.8}$ & 0.5 & 1500 & 150 & b.d.l. & 160 & & b.d.l. & 1810 & & -25.4 & -2 & & -2 & $\mathrm{n}$. & n.m. & -25.8 \\
\hline & & $\mathrm{S} 62 \mathrm{~T}$ & 0.4 & 0.3 & 560 & 13.5 & 12.0 & 0.6 & 19 & 29 & 8 & 10 & b.d.l. & 8 & 74 & b.d.l. & -23.2 & -28.0 & -31.1 & -27.5 & n.m. & $\begin{array}{l}-19.4 \\
\end{array}$ & -25.4 \\
\hline & & $\begin{array}{l}\text { M16 } \\
\text { S25 }\end{array}$ & $\begin{array}{c}\text { n.m. } \\
0.1\end{array}$ & $\begin{array}{l}\text { n.m. } \\
\text { b.d.l. }\end{array}$ & $\begin{array}{c}\text { n.m. } \\
29\end{array}$ & $\begin{array}{c}\text { n.m. } \\
0.1\end{array}$ & $\begin{array}{c}\text { n.m. } \\
0.1\end{array}$ & $\begin{array}{c}\text { n.m. } \\
0.1\end{array}$ & $\begin{array}{l}70 \\
37\end{array}$ & $\begin{array}{c}\text { b.d.l. } \\
7\end{array}$ & $\begin{array}{l}\text { b.d.l. } \\
\text { b.d.l. }\end{array}$ & $\begin{array}{c}\text { b.d.l. } \\
5\end{array}$ & & $\begin{array}{l}\text { b.d.l. } \\
\text { b.d.l. }\end{array}$ & $\begin{array}{l}70 \\
49\end{array}$ & & $\begin{array}{l}-27.0 \\
-23.4\end{array}$ & 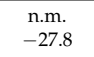 & $\begin{array}{l}n . n \\
n . n\end{array}$ & $\begin{array}{l}\begin{array}{l}\text { n.m. } \\
-29.7\end{array} \\
\end{array}$ & $\begin{array}{l}\text { n.m. } \\
\text { n.m. }\end{array}$ & n.m. & $\begin{array}{l}-27.0 \\
-24.4\end{array}$ \\
\hline & & $\begin{array}{l}525 \\
\text { M17 }\end{array}$ & $\begin{array}{l}0.1 \\
\text { n.m. }\end{array}$ & $\begin{array}{l}\text { b.d.l. } \\
\text { n.m. }\end{array}$ & n.m. & $\begin{array}{l}0.1 \\
\text { n.m. }\end{array}$ & $\begin{array}{l}0.1 \\
\text { n.m. }\end{array}$ & $\begin{array}{c}0.1 \\
\text { n.m. }\end{array}$ & $\begin{array}{l}37 \\
230\end{array}$ & 9 & $\begin{array}{l}\text { b.d.l. } \\
\text { b.d.l. }\end{array}$ & $\begin{array}{l}5 \\
7\end{array}$ & $\begin{array}{l}\text { b.d.l. } \\
\text { b.d.l. }\end{array}$ & $\begin{array}{c}\text { b.d.t. } \\
1\end{array}$ & $\begin{array}{l}49 \\
247\end{array}$ & b.d.l. & $\begin{array}{l}-23.4 \\
-26.9\end{array}$ & $\begin{array}{l}-27.8 \\
\text { n.m. }\end{array}$ & $\begin{array}{l}\text { n.m. } \\
\text { n.m. }\end{array}$ & $\begin{array}{l}\begin{array}{l}-29.7 \\
\text { n.m. }\end{array}\end{array}$ & $\begin{array}{l}\text { n.m. } \\
\text { n.m. }\end{array}$ & $\begin{array}{l}\text { n.m. } \\
\text { n.m. }\end{array}$ & $\begin{array}{l}-24.4 \\
-26.9\end{array}$ \\
\hline
\end{tabular}

Note: Notation is expressed in $\delta \%$ relative to the international standard: Vienna Pee Dee Belemnite (VPDB) for $\delta^{13} \mathrm{C}$ (n.m.: not measured; b.d.l.: below detection limit-for CTs,

b.d.l. refers to each single compound, Dissolved Oxygen (DO), $\mathrm{NO}_{2}{ }^{-}$(Nitrite), $\mathrm{SO}_{4}{ }^{2-}$ (Sulphate), $\mathrm{Fe}_{\text {tot }}$ (Total Iron), $\mathrm{Fe}^{2+}$ (Iron II), Mn ${ }^{2+}$ (Manganese II), Monochlorobenzene (MCB),

1,2-Dichlorobenzene (1,2-DCB), 1,3-Dichlorobenzene (1,3-DCB), 1,4-Dichlorobenzene (1,4-DCB), 1,2,4-Trichlorobenzene (1,2,4-TCB)). 
Groundwater at the site was generally under anoxic conditions, with low DO concentrations ranging between 0.1 and $0.8 \mathrm{mg} \mathrm{L}^{-1}$ (S25 and S70T, respectively; Table 1 and Figure 2), the exception being a relatively high concentration $\left(2.2 \mathrm{mg} \mathrm{L}^{-1}\right)$ in well S67T (Table 1 and Figure 2). With regard to potential electron acceptors, other redox species were found at low concentrations; for example, all nitrate data were below $1 \mathrm{mg} \mathrm{L}^{-1}$ or down to the detection limit (data not shown). Sulphate concentrations ranged from 21 to $1960 \mathrm{mg} \mathrm{L}^{-1}$ (Table 1 and Figure 2). Sulphate data from the eastern sector is reported for samples collected in the downgradient only $\left(29 \mathrm{mg} \mathrm{L}^{-1}\right.$ in S25 and $560 \mathrm{mg} \mathrm{L}^{-1}$ in S61 and S62T); hotspots of high sulphate levels were detected in the western sector: $1960 \mathrm{mg} \mathrm{L}^{-1}$ in the upgradient (968T), and downgradient values of up to 450 and $720 \mathrm{mg} \mathrm{L}^{-1}$ (S72T and S67T, respectively). It is noteworthy that regardless of such differences in sulphate concentrations, which tend to suggest the occurrence of sulphate reduction, the sulphide concentration remained below the detection limit $\left(<0.5 \mathrm{mg} \mathrm{L}^{-1}\right)$ in all the monitoring wells. Similarly, nitrite (with a detection limit of $<0.1 \mathrm{mg} \mathrm{L}^{-1}$ ) was present in very low concentrations (968T, upgradient, western sector), except for S73 (4 mg L ${ }^{-1}$, downgradient, western sector). Concentrations of Fe (II) in groundwater samples were as high as $12 \mathrm{mg} \mathrm{L}^{-1}$, as measured in well $\mathrm{S} 62 \mathrm{~T}$ (western sector, downgradient), whereas the highest values of 22 and $190 \mathrm{mg} \mathrm{L}^{-1}$ refer to wells S76 and 968T located in the downgradient eastern sector (Table 1 and Figure 2). The high Fe (II) concentration values generally correspond to consistent manganese (Mn) content (of up to $0.8 \mathrm{mg} \mathrm{L}^{-1}$; Table 1 and Figure 2). Overall, the redox data indicate that the groundwater system is at least under iron reducing conditions.

\subsection{Contaminants' Spatial Distribution}

\subsubsection{The Western Sector}

High total $\mathrm{CB}$ concentrations were detected, especially in the upgradient of the HB; values ranged between $195 \mu \mathrm{g} \mathrm{L}^{-1}$ (M23) and $19120 \mu \mathrm{g} \mathrm{L}^{-1}$ (S761 Table 1 and Figure 2). In the downgradient, CBs showed lower concentrations, ranging between $12 \mu \mathrm{g} \mathrm{L}^{-1}$ (M18) and $9539 \mu \mathrm{g} \mathrm{L}^{-1}$ (M26; Table 1 and Figure 2).

With regard to specific compounds, the upgradient $\mathrm{MCB}$ concentrations ranged from $83 \mu \mathrm{g} \mathrm{L}^{-1}$ (M23) to $8800 \mu \mathrm{g} \mathrm{L}^{-1}$ (S76), while monitoring wells in the downgradient revealed concentrations of between $12 \mu \mathrm{g} \mathrm{L}^{-1}$ (M18) and $9410 \mu \mathrm{g} \mathrm{L}^{-1}$ (M26; Table 1 and Figure 2).

The upgradient 1,2- and 1,3-DCB concentrations were generally higher compared to those in the downgradient (Table 1). The upgradient 1,2-DCB values ranged between 73 and $3300 \mu \mathrm{g} \mathrm{L}^{-1}$ (M23 and S80, respectively) whereas the 1,3-DCB concentrations reached values of between 66 and $2800 \mu \mathrm{g} \mathrm{L}^{-1}$ (962 and S80, respectively). In the downgradient, 1,2-DCB varied from 22 to $190 \mu \mathrm{g} \mathrm{L}^{-1}$ (M26 and S72T), while concentrations of 1,3-DCB were generally below the detection limit, and only $22 \mu \mathrm{g} \mathrm{L}^{-1}$ was measured in S73. In the case of 1,4-DCB, concentrations were much higher in the upgradient than in the downgradient (Table 1 and Figure 2). The 1,4-DCB measured in the upgradient reached values of between 110 and $2100 \mu \mathrm{g} \mathrm{L}{ }^{-1}$ (968T and S80, respectively) with only a minor amount in $\mathrm{M} 23$, for which a concentration of $39 \mu \mathrm{g} \mathrm{L}^{-1}$ was detected. A different magnitude characterized 1,4 DCB values in the downgradient; values of 25 and $220 \mu \mathrm{g} \mathrm{L}^{-1}$ were detected in M26 and $\mathrm{S} 72 \mathrm{~T}$, respectively.

The available 1,2,4-TCB data characterizes only the upgradient western sector, as most of the other monitoring wells had concentrations below the detection limit. Significant 1,2,4-TCB concentrations were measured in S76 $\left(120 \mu \mathrm{g} \mathrm{L}^{-1}\right)$, S80 $\left(66 \mu \mathrm{g} \mathrm{L}^{-1}\right)$ and $968 \mathrm{~T}\left(19 \mu \mathrm{g} \mathrm{L} \mathrm{L}^{-1}\right.$; Table 1 and Figure 2).

Benzene was also present at the site, where the highest concentration, $6000 \mu \mathrm{g} \mathrm{L}^{-1}$, was detected in the upgradient at S76. The benzene content tended to decrease toward the HB, dropping to $11 \mu \mathrm{g} \mathrm{L}^{-1}$ at $\mathrm{S} 80$. Likewise, in the downgradient, benzene was present at lower concentrations ranging between $82 \mu \mathrm{g} \mathrm{L}{ }^{-1}$ (M26) and $33 \mu \mathrm{g} \mathrm{L}^{-1}$ (S72T; Table 1 and Figure 2).

In addition to CBs, CTs were also detected and were restricted solely to the western sector (Table 1 and Figure 2). The available CT data (e.g., 2-, and 4-chlorotoluene, and 2,3- and 2,6-dichlorotoluene) 
characterize the upgradient area, where concentrations ranged from 11145 down to $189 \mu \mathrm{g} \mathrm{L}{ }^{-1}$ in S76 and 962 , respectively.

In the area in which the production line is still operating, the preprocessing residual waters (WP) revealed a total CB content of $153034 \mu \mathrm{g} \mathrm{L} \mathrm{L}^{-1}$, for which 1,2-DCB was the main contaminant with a concentration of $150465 \mu \mathrm{g} \mathrm{L}^{-1}$ (Table 1). WP samples revealed consistent concentrations of CT of about $21940 \mu \mathrm{g} \mathrm{L}{ }^{-1}$ (Table 1).

The soil sample collected within the western sector at B22 was characterized by CBs as MCB with a concentration of $18009000 \mu \mathrm{g} \mathrm{kg}^{-1}$ (Table 1 and Figure 2).

In summary, the investigation of $\mathrm{CB}$ molar fractions in groundwater samples showed a predominance of DCBs, particularly in the upgradient in wells S80 and 962 (Figure 2). The MCB molar fraction showed a positive trend along the flow system, becoming consistent in the vicinity of the HB (Table 1). A very low molar fraction was registered for 1,2,4-TCB (Table 1).

\subsubsection{The Eastern Sector}

The concentration data for almost all compounds detected in the eastern sector were lower than the values observed in the western sector (Figure 2). Upgradient CB concentrations reached values of 74 and $1810 \mu \mathrm{g} \mathrm{L}^{-1}$ (S62T and S61, respectively), whereas in the downgradient, only minor levels ranged between 49 and $247 \mu \mathrm{g} \mathrm{L}-1$, measured in S25 and M17, respectively.

Regarding specific compounds, upgradient $\mathrm{MCB}$ revealed a higher value of $1500 \mu \mathrm{g} \mathrm{L} \mathrm{L}^{-1}$ in S61 and a concentration of $19 \mu \mathrm{g} \mathrm{L}^{-1}$ in S62T, whereas S25, M16 and M17 showed values ranging between 37 and $230 \mu \mathrm{g} \mathrm{L}{ }^{-1}$ (Table 1 and Figure 2).

In the upgradient, higher concentrations of 1,2- and 1,4-DCB were measured in S61 (150 and $160 \mu \mathrm{g} \mathrm{L}^{-1}$, respectively) in relation to the lower values detected in S62T (29 and $10 \mu \mathrm{g} \mathrm{L}^{-1}$, respectively), which also contained $8 \mu \mathrm{g} \mathrm{L}{ }^{-1}$ of 1,3-DCB. Downgradient data for S25 and M17 wells showed 7 and $9 \mu \mathrm{g} \mathrm{L}^{-1}$ of 1,2-DCB and 5 and $7 \mu \mathrm{g} \mathrm{L}{ }^{-1}$ of 1,4-DCB, respectively (Table 1 and Figure 2).

Benzene was present in the upgradient with a concentration of $8 \mu \mathrm{g} \mathrm{L}^{-1}$ for S62T, while only $1 \mu \mathrm{g} \mathrm{L}^{-1}$ was measured in the downgradient at M17. Lastly, CTs and toluene were absent in this sector (Table 1 and Figure 2).

Three soils samples were collected in the upgradient within the eastern sector (Figure 2). Concentrations of CBs ranged between $52803000 \mu \mathrm{g} \mathrm{kg}^{-1}$ (B41) and $81000 \mu \mathrm{g} \mathrm{kg}{ }^{-1}$ (B71). The B41 data showed a dominance of 1,4-DCB (30843000 $\mathrm{g} \mathrm{kg}^{-1}$ ) over 1,2- and 1,3-DCB (15089 and $4993 \mu \mathrm{g} \mathrm{kg}{ }^{-1}$, respectively) whereas lower concentrations characterized the soil at B71 and B72 (Table 1). A consistent concentration of $20200 \mu \mathrm{g} \mathrm{kg}^{-1}$ in 1,2,3-TCB was detected at the B71 location. No benzene or CTs were present in this sector (Table 1 and Figure 2).

\subsection{CSIA Results}

\subsubsection{The Western Sector}

Figures 2 and $3 \mathrm{~A}$ clearly show that in the upgradient, $\delta^{13} \mathrm{Cs}_{\mathrm{um}}$ was characterized by depleted values ranging from $-30.9 \%$ to $-27.6 \%$ (for $\mathrm{S} 80$ and M23, respectively), while the downgradient wells presented more enriched values (e.g., $-24.5 \%$ in M18). Accordingly, MCB upgradient $\delta^{13} \mathrm{C}$ values varied between $-31.2 \%$ and $-25.9 \%$ (S80 and M23, respectively), and enriched values characterized $\mathrm{MCB}$ in the downgradient groundwater $(-25.5 \%$ for M26; $-24.5 \%$ for M18). Additionally, in the case of 1,2-DCB, data from the upgradient area showed a depleted $\delta^{13} \mathrm{C}$ value of about $-30.4 \%$ o (S80), which became more enriched along the groundwater flowpath toward the HB $(-27.6 \%$; S67T). Enriched 1,2-DCB isotopic signals ranging between $-28.9 \%$ (M26) and $-27.9 \%$ (S73) were detected in the downgradient of the HB. Most of the 1,3-DCB data characterized the upgradient sector; $\delta^{13} \mathrm{C}$ values ranged from $-32.4 \%$ (S76) to $-29.3 \%$ (962), and in the downgradient, the S73 well had a 1,3-DCB isotopic composition of $-31.3 \%$. The same trend was observed for 1,4-DCB with upgradient $\delta^{13} \mathrm{C}$ 
values ranging from $-30.1 \%$ to $-28.9 \%$ ( $\mathrm{S} 80$ and $\mathrm{M} 23$, respectively) and enriched $\delta^{13} \mathrm{C}$ values in the downgradient of approximately $-28 \%$ (M26, S72T and S73).
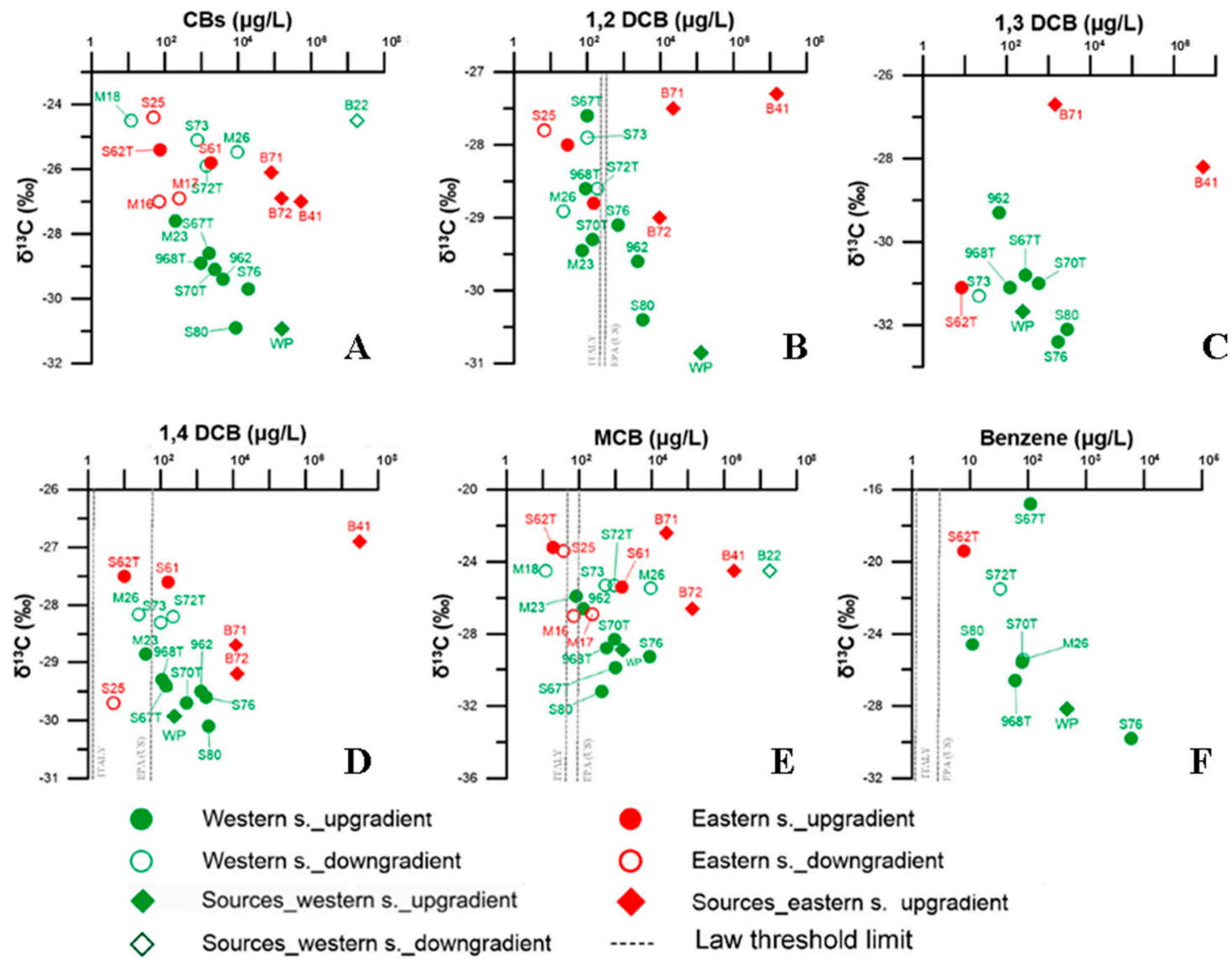

Figure 3. Scatterplots of concentration versus $\delta^{13} \mathrm{C}$ of total chlorobenzenes (CBs) (A), 1,2-dichlorobenzene (DCB) (B), 1,3-DCB (C), 1,4-DCB (D), MCB (E) and benzene (F). Green and red circles refer to wells located in the western and eastern sectors, respectively; green and red rhombuses refer to the sources, soil samples (B-) and processing waters (WP). Concentrations are expressed in $\mu \mathrm{g} \mathrm{L}^{-1}$ and $\mu \mathrm{g} \mathrm{kg}^{-1}$ for groundwater and soil samples, respectively. Empty and filled symbols refer to the downgradient and upgradient of the hydraulic barrier, respectively. Data are shown in Table 1. See Figure 2 for sample locations.

A wide variation in the benzene isotopic composition was observed in the upgradient; $\delta^{13} \mathrm{C}$ values ranged between $-29.8 \%$ in $\mathrm{S} 76$ and $-16.8 \%$ in S67T. In the downgradient, benzene signatures varied from $-25.5 \%$ in M26 to $-21.5 \%$ in S72T (Table 1 and Figures 2 and 3F). 1,2,4-TCB was detected only in the upgradient and the $\delta^{13} \mathrm{C}$ values ranged between $-33.3 \%$ and $-30.4 \% 0$ ( $\mathrm{S} 80$ and 968T, respectively; Table 1 and Figure 2). The sample collected from the potential upgradient source, WP, had a $\delta^{13} \mathrm{C}_{\text {sum }}$ value of $-30.9 \%$ (Table 1 and Figures 2 and 3). A similar isotopic composition was measured for

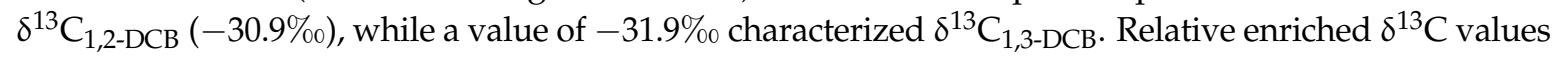
were observed for 1,4-DCB (-29.9\%), MCB and benzene ( $-28.8 \%$ and $-28.0 \%$, respectively). The soil sample collected within the western sector in the downgradient of the $\mathrm{HB}$ (B22) had a $\delta^{13} \mathrm{C}_{\text {sum }}$ signature of $-24.5 \%$, likely representing the isotopic composition for MCB (Table 1 and Figures 2 and 3).

\subsubsection{The Eastern Sector}

The little data available for the eastern sector generally showed more enriched $\delta^{13} C_{\text {sum }}$ values compared to that of the western area: in the upgradient, $\delta^{13} \mathrm{C}_{\text {sum }}$ values were $-25.8 \%$ and $-25.4 \%$ o 
(S61 and S62T), and the downgradient data ranged between $-27.0 \%$ and $-24.4 \% 0$ (M16 and S25, respectively; Table 1 and Figures 2 and $3 \mathrm{~A}$ ).

The S61 and S62T wells, located in the upgradient, showed consistent differences in the ${ }^{13} \mathrm{C}_{\mathrm{MCB}}$ isotopic composition ( $-25.4 \%$ and $-23.2 \%$, respectively), whereas similar signatures were observed for $\delta^{13} \mathrm{C}_{1,2-\mathrm{DCB}}(-28.8 \%$ and $-28.0 \%)$ and $\delta^{13} \mathrm{C}_{1,4-\mathrm{DCB}}(-27.6 \%$ and $-27.5 \%)$. The $\delta^{13} \mathrm{C}_{1,3-\mathrm{DCB}}$ and $\delta^{13} C_{\text {benzene }}$ data collected at only one well (S62T) had values of $-31.1 \%$ and $-19.4 \%$, respectively (Table 1 and Figure 2). In the downgradient, the $\mathrm{CBs}$ detected were representative of only $\mathrm{MCB}$; $\delta^{13} \mathrm{C}_{\mathrm{MCB}}$ values ranged between $-27.0 \%$ and $-23.4 \%$ (M16 and S25, respectively). In well S25, 1,2and 1,4-DCB were also present with values of $-27.8 \%$ and $-29.7 \%$, respectively (Table 1 and Figures 2 and 3$)$.

The three soil samples collected showed only minor variations in $\delta^{13} \mathrm{C}_{\text {sum }}$, ranging from $-27.0 \%$ (B41) to $-26.1 \%$ (B71). Individual compounds covered a wide isotope range in $\delta^{13} \mathrm{C}_{\mathrm{MCB}}$ data $(-26.6 \%$ to $-22.4 \%$ at $B 72$ and $B 71$, respectively). $B 41$ and $B 71$ had $\delta^{13} C_{1,2-D C B}$ values of $-27.3 \%$ and $-27.5 \%$, whereas a depleted signal of $-29.0 \%$ was measured in B72. A wider range was observed for $\delta^{13} \mathrm{C}_{1,4-\mathrm{DCB}}$, for which an isotopic signal of $-26.9 \%$ was measured in $\mathrm{B} 41$, while depleted values were measured for B71 and B72 $(-28.7 \%$ and $-29.2 \%)$. $\delta^{13} \mathrm{C}_{1,3-\mathrm{DCB}}$ data showed a value of $-28.2 \%$ for $\mathrm{B} 41$ and of $-26.7 \%$ for $\mathrm{B} 71$, while $\delta^{13} \mathrm{C}_{1,2,4-\mathrm{TCB}}$ data was available only for $\mathrm{B} 71$, with a signature of $-29.6 \%$ (Table 1 and Figures 2 and 3).

\section{Discussion}

1,4- and 1,2-DCB, MCB and benzene concentrations were consistently above the MCLs in most upgradient wells in both the western and eastern sectors (Figure 3); only 1,2,4-TCB remained below the MCL. 1,3-DCB also showed very high concentrations, although no MCL was officially established. In the downgradient of the $\mathrm{HB}$, concentrations were 1 to 2 orders of magnitude lower than those in the upgradient for all target compounds, with concentrations below the MCLs at most monitoring wells. Although the HB seemed to reduce and contain the spreading of the contaminants, concentrations in a few wells, such as S72T for 1,4-DCB, MCB and benzene, and M16 and M26 for MCB, were still above the MCLs. To understand if these high concentrations were related to the upgradient plumes (i.e., related to a HB malfunctioning) or from other sources located in the downgradient area, a SA approach is presented using the molar fraction and $\delta^{13} \mathrm{C}_{\text {sum }}$ data. In addition, $\delta^{13} \mathrm{C}$ data for each specific compound detected have been used to assess potential biodegradation processes at the site.

\subsection{Source Apportionment}

Examination of the molar fraction data from both sectors indicated a trend along the groundwater flowpath, where an increase in MCB was coupled with a decrease in DCBs (Figure 2). Therefore, a similar retardation was presumed for MCB and DCBs (almost identical adsorption coefficients [29]) and no significant effect on the molar fraction distribution was expected. Because of transport processes, a similar trend could also be related to potential anaerobic biodegradation in the upgradient. To overcome the high degree of uncertainty when using the molar fraction for SA purposes, an analysis was conducted on the basis of $\delta^{13} \mathrm{C}_{\text {sum. }}$. As several contaminants were detected at the site and potential biodegradation can be hypothesized from the molar fraction distribution (Figure 2), the approach presented made use of the isotope balance $\delta^{13} \mathrm{C}_{\text {sum }}$ rather than considering the isotopic signature of specific compounds (Table 1) [13,30]. Yet, if contaminants undergo a preferential transport along the plumes and/or when biodegradation processes are taking place, the $\delta^{13} C_{\text {sum }}$ interpretation is not an easy task [31]. However, assuming that the carbon pool is conservative during anaerobic biodegradation (supposing DCBs $\rightarrow \mathrm{MCB} \rightarrow$ benzene) [32,33] and that aerobic processes are not inducing significant fractionations, particularly for $\mathrm{CBs}[23-25], \delta^{13} \mathrm{C}_{\text {sum }}$ values should retain their signature along the flowpath, regardless of the occurrence of degradation. Eventually, with further degradation and mineralization of benzene to $\mathrm{CO}_{2}, \delta^{13} \mathrm{C}_{\text {sum }}$ could show an enrichment along the plume [32,33]. On the basis of this, if significant deviations from the $\delta^{13} C_{\text {sum }}$ initial composition are 
observed, this may indicate different sources and/or a mixture of contaminants derived from distinct plumes, particularly if depletion occurs along the plumes.

In the upgradient, $\delta^{13} \mathrm{C}_{\text {sum }}$ values show a clear distinction between the western and eastern sectors, with average values of around $-29.4 \%$ and $-25.6 \%$, respectively (and average concentrations of 5259 and $942 \mu \mathrm{g} \mathrm{L}{ }^{-1}$, respectively), confirming that contamination has different origins; this distinction is confirmed by the fact that CTs were detected only in the western sector.

When considering the western sector and following the groundwater flow, S73 and S72T located in the downgradient revealed isotopic values $\left(\delta^{13} \mathrm{C}_{\text {sum }}\right)$ that were approximately $3 \%$ more enriched than in the upgradient at S67T and 968T, despite that all samples were characterized by similar total $\mathrm{CB}$ concentrations (on average $1185 \mu \mathrm{g} \mathrm{L}{ }^{-1}$; Table 1 and Figure 3A). Accordingly, the downgradient M26 was enriched compared to the upgradient S80 and S70T, which contained similar or higher total CB concentrations than the respective upgradient wells $\left(9539 \mu \mathrm{g} \mathrm{L}^{-1}\right.$ for M26, $8697 \mu \mathrm{g} \mathrm{L}^{-1}$ for S80 and $2309 \mu \mathrm{g} \mathrm{L}{ }^{-1}$ for S70T). The enriched signatures measured in the downgradient could not be explained by degradation or transport processes (for which a change in total concentrations is expected), while they were likely indicative of an independent plume contributing to these wells and that was not related to the upgradient wells (Table 1 and Figure 3A). Lastly, a large enrichment $(-24.5 \%$ o coupled with a significant reduction in the $\mathrm{CB}$ concentration $\left(12 \mu \mathrm{g} \mathrm{L} \mathrm{L}^{-1}\right)$ was observed at M18 when compared to the respective upgradient wells; in this case, it was not possible to infer a clear distinction between the effects of potential biodegradation processes and contaminants originating from a different plume (Table 1 and Figure 3A).

The distribution of contaminants in the eastern sector lacked a clear trend for $\delta^{13} \mathrm{C}_{\text {sum }}$ along the flowpath, thereby indicating the existence of different residual sources in this area (Figure 2). In the downgradient, M16 and M17 showed much more depleted $\delta^{13} \mathrm{C}_{\text {sum }}$ values in comparison to the upgradient $\mathrm{S} 61$ and S62T, thus eliminating any possible correlation between the plumes detected in the upgradient and downgradient of the HB (Table 1 and Figure 3A).

In order to address a potential source for the detected plumes, a comparison of the compounds' isotopic signatures measured among the wells, in those of WP (processing water) and those measured within the soils, was conducted. For the western sector, $\delta^{13} C_{\text {sum }}$ compositions for the upgradient wells were consistent with the isotopic signals characterizing WP, suggesting a potential correlation among this source and dissolved contaminants (Table 1 and Figure 3A). This mainstay was then confirmed by the high CT concentration found in WP, which was consistent with that detected in the nearby groundwater (Table 1). The same assumption could be made for the downgradient, where the soil at B22 was characterized by an enriched value of $-24.5 \%$, which was in the same range as the $\delta^{13} C_{\text {sum }}$ values measured in the groundwater (Table 1 and Figure $3 \mathrm{~A}$ ).

In the eastern sector, the upgradient wells $\mathrm{S} 61$ and $\mathrm{S} 62 \mathrm{~T}$ showed similar $\delta^{13} \mathrm{C}_{\text {sum }}$ values with respect to the soil isotopic composition measured in B71, indicating that here, dissolved contaminants were related to the impacted soil, most likely by the industrial activity prior to the 1980s (Table 1 and Figure 3A).

Indeed, the current production system seems to make use of more isotopically depleted compounds compared to past production at the original facility. Additionally, the presence of other contaminants, such as CTs in the western sector, indicate changes in the production process over time.

\subsection{Biodegradation}

As previously mentioned, $\mathrm{DCB}$ reduction and $\mathrm{MCB}$ molar fractions increased along the flowpath, indicating possible biodegradation processes, particularly in the upgradient of the HB. Overall, the groundwater geochemistry data indicated potential Fe- and Mn-reducing conditions, particularly in the upgradient of the HB. Several authors suggest Fe-reducing conditions as suitable for CBs reduction [34]. Dermietzel and Vieth [34] documented complete degradation for 1,4-DCB but only partial degradation for 1,2- and 1,3-DCB with Fe (III) species serving as electron acceptors, whereas Stelzer at al. [28] demonstrated partial MCB degradation under ferric iron-reducing conditions. 
The occurrence of biodegradation processes was also supported by slight enrichments observed in $\delta^{13} C_{\text {sum }}$ along the flowpath.

Because of the complexity of the site, biodegradation was inferred only in the upgradient in the western sector, where most of the wells with significant $\mathrm{CB}$ concentrations are located.

A decrease in the 1,2,4-TCB concentration was related to an enrichment in $\delta^{13} \mathrm{C}_{1,2,4-\mathrm{TCB}}$, suggesting that biodegradation is active in this area (Table 1 ). Because aerobic degradation does not induce ${ }^{13} \mathrm{C}$ fractionation [23,26], 1,2,4-TCB is most likely degraded by anaerobic transformation. As a result of the relatively low 1,2,4-TCB concentration, its biodegradation with the potential generation of DCBs does not represent an urgent environmental issue at this time.

On the other hand, the high DCB molar fractions were consistent with those measured in several potential sources (e.g., WP; Figure 2), indicating DCBs as the main parent compounds present at the site. On the basis of this, $\delta^{13} \mathrm{C}_{\mathrm{DCBs}}$ can be interpreted by applying the Rayleigh equation (Equation (3)), avoiding complications associated with compounds that are in turn degraded and/or generated as a product from other degradative reactions. Only a few enrichment factors $(\varepsilon)$ are available for anaerobic degradation of DCBs. Liang at al. [26] estimated, on the laboratory scale, $\varepsilon$ values of $-0.8 \%$, $-5.4 \%$ and $-6.3 \%$ for $1,2-, 1,3-$ and $1,4-\mathrm{DCB}$, respectively. The scarce information from literature allows for a more qualitative estimation of the extent of biodegradation, leading to broader quantitative estimates when additional enrichment factors are available. An additional limitation in the estimate is the lack of information about DCBs' $\varepsilon$ values for aerobic degradation. Several studies have shown no significant ${ }^{13} \mathrm{C}$ fractionation for TCBs or MCB under aerobic conditions, and it is likely that DCBs would behave similarly, thus excluding ${ }^{13} \mathrm{C}$ fractionation for aerobic degradation pathways (expected to occur via dioxygenase, which would not induce significant ${ }^{13} \mathrm{C}$ fractionation).

In Figure $3 \mathrm{~B}-\mathrm{D}$, good correlations between $\delta^{13} \mathrm{C}_{\mathrm{DCBs}}$ versus DCB concentrations are shown. Along two of the plumes, it is estimated that $25 \%$ of $1,3-\mathrm{DCB}$ was removed by degradation (Figure 3C) in the proximity of the HB (e.g., in S67T and S70T). This was determined by using an $\varepsilon$ value of $-5.4 \%$ [26], and -32.4 and $-32.1 \%$ as initial $\delta^{13} \mathrm{C}_{1,3-\mathrm{DCB}}$ values (S76 and $\mathrm{S} 80$, respectively). Additionally, a trend of $\delta^{13} \mathrm{C}_{1,2-\mathrm{DCB}}$ versus concentrations of 1,2-DCB yielded a significant Rayleigh correlation for 1,2-DCB (Figure 3B). A high removal of up to $95 \%$ was estimated in the HB vicinity (S70T) by using an $\varepsilon$ value of $-0.8 \%$ [ [26] and $-30.9 \%$ as the initial $\delta^{13} \mathrm{C}_{1,2-\mathrm{DCB}}$ value (WP) along the western plume. In addition, a 75\% removal was estimated for the other plume between S76, S67T and 968T. A lower degradation of 1,4-DCB occurs (e.g., M23), as indicated by the smaller enrichments [26].

The overall $\delta^{13} \mathrm{C}$ enrichment was most likely indicative of anaerobic degradation of DCBs (Figure 3B-D). As such, a significant generation of $\mathrm{MCB}$ as a degradation product was expected, further complicating the interpretation of $\delta^{13} \mathrm{C}$ data. As a consequence, $\delta^{13} \mathrm{C}_{\mathrm{MCB}}$ versus concentration data do not follow a definite Rayleigh trend, as for the DCBs (Figure 3E). MCB concentrations increased in S70T, S80 and 968T, whereas a depletion was observed in $\delta^{13} \mathrm{C}_{\mathrm{MCB}}$ values in 968T, S76 and S67T (Table 1 and Figure 3E). This behavior was a direct indication that along the groundwater flow, MCB represents a reaction by-product, particularly where DCB biodegradation processes take place, and thus confirming the anaerobic nature of DCBs degradation. Although a reactive transport model is needed for a conclusive $\delta^{13} \mathrm{C}_{\mathrm{MCB}}$ data interpretation, some further reasoning can be inferred. An enriched $\delta^{13} C_{M C B}$ value of $-28.3 \%$ compared to $\delta^{13} C_{D C B s}$ values ranging from $-29.3 \%$ to $-31.0 \%$ leads to hypothesizing further anaerobic MCB degradation to benzene in the vicinity of S70T [25]. On the contrary, where $\delta^{13} C_{M C B}$ values remained depleted compared to $\delta^{13} C_{D C B s}$ values (S80 and S67T), local anaerobic biodegradation of MCB is not likely to be occurring. This evidence is reinforced by benzene concentration and $\delta^{13} C_{\text {benzene }}$ data (Table 1 and Figure $3 F$ ). Benzene was also detected within the potential source (WP), masking the possibility to discern benzene derived by $\mathrm{MCB}$ anaerobic degradation from the consideration of it as an initial contaminant. Moreover, it should be considered that benzene can be mineralized (to $\mathrm{CO}_{2}$ ), hence clouding the understanding of which degradation process is dominant at the site. Data from wells S80 to S70T showed a trend towards an increase in the benzene concentration coupled with a depletion in $\delta^{13} C_{\text {benzene, }}$, confirming 
that benzene is generated as a consequence of anaerobic MCB biodegradation. On the contrary, little evidence supports the occurrence of benzene degradation. Degradation was observed in S76 and S67T, where a decrease in the benzene concentration was coupled with an overall enrichment trend for $\delta^{13} C_{\text {benzene }}$ (Table 1 and Figure 3F). Unfortunately, no insights into potential MCB aerobic biodegradation processes can be made on the basis of $\delta^{13} \mathrm{C}$, as no fractionation is expected to occur under these conditions. Furthermore, it is not possible to distinguish between aerobic or anaerobic biodegradation of benzene solely on the basis of on $\delta^{13} \mathrm{C}$, as similar $\varepsilon$ values of approximately $-1.5 \%$ and 3.5\% have been estimated under both aerobic and anaerobic biodegradation conditions [13].

In general, $\delta{ }^{13} \mathrm{C}_{\text {sum }}$ values showed a slight ${ }^{13} \mathrm{C}$ enrichment along the flow path, suggesting that overall, the $\mathrm{CBs}$ are being degraded and partially removed. $\delta^{13} \mathrm{C}_{\mathrm{DCBs}}$ indicate biodegradation, most likely anaerobic, with 1,2-DCB preferentially degraded over 1,3- and 1,4-DCB. MCB was found in the aquifer mainly as product of DCB biodegradation, and there is evidence of further anaerobic degradation to benzene in some areas, for example in the vicinity of S70T, which in turn, seemed to be degraded in the shallow part of aquifer. Lastly, benzene degradation could potentially explain the overall $\delta^{13} \mathrm{C}_{\text {sum }}$ enrichment along the flow path, particularly from S80 to S70T (Figure 3).

Fe- and Mn-reducing conditions at the field site are favorable to anaerobic biodegradation of DCBs; the 1,4-DCB preferential degradation was in line with findings from [34]. In addition, evidence of partial MCB degradation was observed where the reducing conditions were more pronounced (S70T). The results from this study confirm that Fe- and Mn-reducing conditions agree with the preferential occurrence of anaerobic CB degradation, particularly for TCB and DCB (particularly 1,4-DCB), without loss of the less amenable MCB.

\section{Conclusions}

The proposed approach using CSIA supported by hydrogeological, concentration and redox data proved to be an effective tool for detailed site characterization. The isotopic investigation revealed consistent differences in the signature of contaminants detected in the western and eastern sectors, suggesting variations in factory production processes over time.

In summary, CSIA was applied successfully for SA, and more specifically, the use of the concentration-weighted average $\delta^{13} \mathrm{C}_{\text {sum }}$ was crucial in the understanding of how the plumes in the downgradient of the $\mathrm{HB}$ are not connected with the upgradient contamination. Thus, this indicates that the source of the downgradient plume is associated to contaminated soils, most likely as a result of past chemical-waste disposal activities. Furthermore, CSIA has highlighted the importance of biodegradation processes for contaminant containment in the upgradient of the HB.

With regard to specific compounds, the $\delta^{13} \mathrm{C}$ results for 1,2,4-TCB, and DCBs are indicative of biodegradation, most likely anaerobic, with 1,2-DCB preferentially degraded over 1,3- and 1,4-DCB. $\mathrm{MCB}$ was found in the aquifer mainly as a by-product of DCB biodegradation. In addition, isotope patterns provided evidence that $\mathrm{MCB}$ undergoes anaerobic degradation to benzene, and benzene degradation has also been shown to occur.

The present study demonstrates the utility of applying CSIA for the characterization of contaminated sites impacted by CBs. Furthermore, the study demonstrates the need for further scientific efforts to reach a comprehensive understanding of the degradation pathways of $C B$ and its isotopic patterns, which is an area that is still sparsely documented.

Acknowledgments: We would like to thank the Politecnico di Milano for the Postdoctoral International Fellowship (PIF) to Massimo Marchesi. Thanks are also due to Umberto Traldi, Thermo Fisher Scientific, for his kind help and assistance with isotope analysis. We would like to thank Richard Elgood from the University of Waterloo for revising the English grammar.

Author Contributions: L.A. and P.T. conceived and designed the site investigation; M.M. performed the CSIA analysis; R.A. contributed by supervising during the study implementation and by assisting with data interpretation; L.A. and M.M. wrote the paper. 
Conflicts of Interest: The authors declare no conflict of interest. The founding sponsors had no role in the design of the study; in the collection, analyses, or interpretation of data; in the writing of the manuscript; or in the decision to publish the results.

\section{References}

1. Panagos, P.M.; Liedekerke, V.; Yigini, Y.; Montanarella, L. Contaminated sites in Europe: Review of the current situation based on data collected through a European network. J. Environ. Public Health 2013, 2013. [CrossRef] [PubMed]

2. Lawrence, S.J. Description, Properties, and Degradation of Selected Volatile Organic Compounds Detected in Ground Water-A Review of Selected Literature; Open-File Report 2006-1338; U.S. Geological Survey: Atlanta, GA, USA, 2006.

3. Field, J.A.; Sierra-Alvarez, R. Microbial degradation of chlorinated benzenes. Biodegradation 2008, 19, 463-480. [CrossRef] [PubMed]

4. Alberti, L.; Lombi, S.; Zanini, A. Identifying sources of chlorinated aliphatic hydrocarbons in a residential area in Italy using the integral pumping test method. Hydrogeol. J. 2011, 19, 1253-1267. [CrossRef]

5. Filippini, M.; Amorosi, A.; Campo, B.; Herrero-Martìn, S.; Nijenhuis, I.; Parker, B.; Gargini, A. Origin of VC-only plumes from naturally enhanced dechlorination in a peat-rich hydrogeologic setting. J. Contam. Hydrol. 2016, 192, 129-139. [CrossRef] [PubMed]

6. Nijenhuis, I.; Schmidt, M.; Pellegatti, E.; Paramatti, E.; Richnow, H.H.; Gargini, A. A stable isotope approach for source apportionment of chlorinated ethene plumes at a complex multi-contamination events urban site. J. Contam. Hydrol. 2013, 153, 92-105. [CrossRef] [PubMed]

7. Petitta, M.; Pacioni, E.; Sbarbati, C.; Corvatta, G.; Fanelli, M.; Aravena, R. Hydrodynamic and isotopic characterization of a site contaminated by chlorinated solvents: Chienti River Valley, Central Italy. Appl. Geochem. 2013, 32, 164-174. [CrossRef]

8. Schmidt, T.C.; Jochmann, M.A. Origin and fate of organic compounds in water: Characterization by compound-specific stable isotope analysis. Annu. Rev. Anal. Chem. 2012, 5, 133-155. [CrossRef] [PubMed]

9. Shaouakar-Stash, O.; Frape, S.K.; Aravena, R.; Gargini, A.; Pasini, M.; Drimmie, R.J. Analysis of compound-specific chlorine stable isotopes of vinyl chloride by continuous flow-isotope ratio mass spectrometry (FC-IRMS). Environ. Forensics 2009, 10, 299-306. [CrossRef]

10. Stroo, H.F.; Ward, C.F. In Situ Remediation of Chlorinated Solvent Plumes; Springer: New York, NY, USA, 2010.

11. Alberti, L.; Alimi, H.; Ertel, T.; Trefiletti, P.; Pietrini, I. Fingerprinting and groundwater model application to evaluate hydraulic barrier efficiency (Italy). Environ. Forensics 2015, 16, 217-230. [CrossRef]

12. Colombo, L.; Cantone, M.; Alberti, L.; Francani, V. Analytical solutions for multiwell hydraulic barrier capture zone defining. Ital. J. Eng. Geol. Environ. 2012, 12, 17-33.

13. Hunkeler, D.; Meckenstock, R.U.; Sherwood-Lollar, B.; Schmidt, T.C.; Wilson, J.T. A Guide for Assessing Biodegradation and Source Identification of Organic Groundwater Contaminants Using Compound Specific Isotope Analysis (CSIA); U.S. Environmental Protection Agency: Washington, DC, USA, 2009.

14. Lojkasek-Lima, P.; Aravena, R.; Shouakar-Stash, O.; Frape, S.K.; Marchesi, M.; Fiorenza, S.; Vogan, J. Evaluating TCE Abiotic and Biotic Degradation Pathways in a Permeable Reactive Barrier Using Compound Specific Isotope Analysis. Ground Water Monit. R. 2012, 32, 53-62. [CrossRef]

15. Van Breukelen, B.M. Extending the Rayleigh equation to allow competing isotope fractionating pathways to improve quantification of biodegradation. Environ. Sci. Technol. 2007, 41, 4004-4010. [CrossRef] [PubMed]

16. Sherwood Lollar, B.; Slater, G.F.; Sleep, B.; Witt, M.; Klecka, G.M.; Harkness, M.; Spivack, J. Stable carbon isotope evidence for intrinsic bioremediation of tetrachloroethene and trichloroethene at area 6, Dover Air Force Base. Environ. Sci. Technol. 2001, 35, 261-269. [CrossRef] [PubMed]

17. Rügner, H.; Finkel, M.; Kaschl, A.; Bittens, M. Application of monitored natural attenuation in contaminated land management-A review and recommended approach for Europe. Environ. Sci. Policy 2006, 9, 568-576. [CrossRef]

18. Illman, W.A.; Alvarez, P.J. Performance assessment of bioremediation and natural attenuation. Crit. Rev. Environ. Sci. Technol. 2009, 39, 209-270. [CrossRef] 
19. Malcolm, H.; Howe, P.; Dobson, S. Chlorobenzenes Other than Hexachlorobenzene: Environmental Aspects; World Health Organization: Geneva, Switzerland, 2004; Available online: http://www.who.int/iris/handle/ 10665/42905 (accessed on 15 August 2017).

20. Barber, J.L.; Sweetman, A.J.; Van Wijk, D.; Jones, K.C. Hexachlorobenzene in the global environment: Emissions, levels, distribution, trends and processes. Sci. Total Environ. 2005, 349, 1-44. [CrossRef] [PubMed]

21. Sims, J.L.; Suflita, J.M.; Russell, H.H. Reductive Dehalogenation of Organic Contaminants in Soils and Ground Water; U.S. Environmental Protection Agency: Washington, DC, USA, 1991.

22. Liang, X.; Devine, C.E.; Nelson, J.; Sherwood Lollar, B.; Zinder, S.; Edwards, E.A. Anaerobic conversion of chlorobenzene and benzene to $\mathrm{CH} 4$ and $\mathrm{CO} 2$ in bioaugmented microcosms. Environ. Sci. Technol. 2013, 47, 2378-2385. [CrossRef] [PubMed]

23. Griebler, C.; Adrian, L.; Meckenstock, R.U.; Richnow, H.H. Stable carbon isotope fractionation during aerobic and anaerobic transformation of trichlorobenzene. FEMS Microbiol. Ecol. 2004, 48, 313-321. [CrossRef] [PubMed]

24. Kaschl, A.; Vogt, C.; Uhlig, S.; Nijenhuis, I.; Weiss, H.; Kästner, M.; Richnow, H.H. Isotopic fractionation indicates anaerobic monochlorobenzene biodegradation. Environ. Toxicol. Chem. 2005, 24, 1315-1324. [CrossRef] [PubMed]

25. Liang, X.; Howlett, M.R.; Nelson, J.L.; Grant, G.; Dworatzek, S.; Lacrampe-Couloume, G.; Zinder, S.H.; Edwards, E.A.; Sherwood Lollar, B. Pathway-dependent isotope fractionation during aerobic and anaerobic degradation of monochlorobenzene and 1,2,4-trichlorobenzene. Environ. Sci. Technol. 2011, 45, 8321-8327. [CrossRef] [PubMed]

26. Liang, X.; Mundle, S.O.; Nelson, J.L.; Passeport, E.; Chan, C.C.; Lacrampe-Couloume, G.; Zinder, S.H.; Sherwood Lollar, B. Distinct carbon isotope fractionation during anaerobic degradation of dichlorobenzene isomers. Environ. Sci. Technol. 2014, 48, 4844-4851. [CrossRef] [PubMed]

27. Braeckevelt, M.; Rokadia, H.; Imfeld, G.; Stelzer, N.; Paschke, H.; Kuschk, P.; Weber, S. Assessment of in situ biodegradation of monochlorobenzene in contaminated groundwater treated in a constructed wetland. Environ. Pollut. 2007, 148, 428-437. [CrossRef] [PubMed]

28. Stelzer, N.; Imfeld, G.; Thullner, M.; Lehmann, J.; Poser, A.; Richnow, H.; Nijenhuis, I. Integrative approach to delineate natural attenuation of chlorinated benzenes in anoxic aquifers. Environ. Pollut. 2009, 157, 1800-1806. [CrossRef] [PubMed]

29. Thullner, M.; Schäfer, W. Modeling of a field experiment on bioremediation of chlorobenzenes in groundwater. Bioremediat. J. 1999, 3, 247-267. [CrossRef]

30. Palau, J.; Marchesi, M.; Chambon, J.C.; Aravena, R.; Canals, A.; Binning, P.J.; Soler, A. Multi-isotope (carbon and chlorine) analysis for fingerprinting and site characterization at a fractured bedrock aquifer contaminated by chlorinated ethenes. Sci. Total Environ. 2014, 475, 61-70. [CrossRef] [PubMed]

31. Van Breukelen, B.M.; Hunkeler, D.; Volkering, F. Quantification of sequential chlorinated ethene degradation by use of a reactive transport model incorporating isotope fractionation. Environ. Sci. Technol. 2005, 39, 4189-4197. [CrossRef] [PubMed]

32. Bloom, Y.; Aravena, R.; Hunkeler, D.; Edwards, E.; Frape, S.K. Carbon isotope fractionation during microbial dechlorination of trichloroethene, cis-1, 2-dichloroethene, and vinyl chloride: Implications for assessment of natural attenuation. Environ. Sci. Technol. 2000, 34, 2768-2772. [CrossRef]

33. Hunkeler, D.; Chollet, N.; Pittet, X.; Aravena, R.; Cherry, J.A.; Parker, B.L. Effect of source variability and transport processes on carbon isotope ratios of TCE and PCE in two sandy aquifers. J. Contam. Hydrol. 2004, 74, 265-282. [CrossRef] [PubMed]

34. Dermietzel, J.; Vieth, A. Chloroaromatics in groundwater: Chances of bioremediation. Environ. Geol. 2002, 41, 683-689.

(C) 2017 by the authors. Licensee MDPI, Basel, Switzerland. This article is an open access article distributed under the terms and conditions of the Creative Commons Attribution (CC BY) license (http:/ / creativecommons.org/licenses/by/4.0/). 